\title{
Energy management system and supervision in a micro-grid using artificial neural network technique
}

\author{
Ezzitouni Jarmouni $^{1}$, Ahmed Mouhsen ${ }^{2}$, Mohammed Lamhammedi ${ }^{3}$, Hicham Ouldzira ${ }^{4}$ \\ ${ }^{1,3}$ Hassan First University of Settat, The Faculty of Sciences and Technology, Laboratory of Radiation-Matter \\ and Instrumentation (RMI), Morocco \\ ${ }^{2,4}$ Hassan First University of Settat, The Faculty of Sciences and Technology, Laboratory of Engineering, \\ Industrial Management and Innovation (IMII), Morocco
}

\begin{tabular}{l} 
Article Info \\
\hline Article history: \\
Received Aug 6, 2021 \\
Revised Sep 28, 2021 \\
Accepted Oct 8, 2021 \\
\hline
\end{tabular}

Keywords:

Artificial neural network

Bidirectional DC/DC

Energy management system

Photovoltaic panel

Renewable energy

Solar battery

Supervisions

\begin{abstract}
Nowadays, the combination of conventional and renewable energy sources such as solar energy is one of the most widespread solutions to surmount the challenge of the climate and energy crisis. In the presence of random behavior of photovoltaic systems and variable power demand by consumers, energy management is a real challenge. In this paper, we propose a new energy management technique based on artificial neural networks in a smart grid. This will ensure the continuous supply of electricity to the consumer in the presence of random operation in energy consumption and generation. The global system is modeled and simulated under the MATLAB/Simulink tool.
\end{abstract}

This is an open access article under the CC BY-SA license.

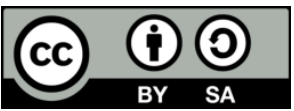

\section{Corresponding Author:}

Jarmouni Ezzitouni

Laboratory of Radiation-Matter and Instrumentation (RMI)

Hassan First University of Settat, The Faculty of Sciences and Technology

BP: 577, route de Casablanca. Settat, Morocco

Email: ezzitouni.jarmouni@gmail.com

\section{INTRODUCTION}

Due to climate change and the rapid depletion of conventional energy sources, renewable energy technology is becoming more popular day by day. According to the latest renewable energy market forecast by the international energy agency affairs (IEA), the world's renewable electric power capacity will rise by 1200 gigawatts by 2024 due to reductions in cost [1]. The solar PV system can reduce carbon emissions and provide clean energy but may not be able to supply the load requirements due to sudden changes in weather conditions and when the solar irradiation is weak. The battery storage system also improves the system dynamics for sudden weather changes [2], [3].

To ensure the balance of production and consumption, energy storage systems are needed. And for the energy system to be more reliable, a link to the public grid is a suitable solution, especially when we have a critical load. In a bid to make optimal use of the energy produced and to cover the energy needs of consumers at all times, reliable energy management techniques between the energy produced and the consumption are essential. With the growth in the rate of integration of renewable energy sources, along with conventional sources and the solutions of distribution of electric power generation units, energy management system has become more interesting. In the literature we find various papers concerning electric energy management system (EMS). In this part, we will provide some examples; Cheng et al. [4] provided a complete review of 
the microgrid energy management system. Subjects covered include the essential constituents of a microgrid, comparability between distributed, centralized implementations and control approaches. Shareef et al. [5] considered home energy management system (HEMS) with respect to the consideration of demand response (DR), intelligent technologies and intelligent controllers. Residential demand response schemes in the HEMS system are contrasted, and artificial intelligence applications for scheduling the load in the HEMS system are also maintained. Rafique and Jianhua [6] reported on HEMS, production and load predictors, with intensive reviews on both the primary and secondary micro-grid monitoring, including prediction and forecasting approaches for wind, solar and load. Khan et al. [7] introduce the role of multi-agent systems for distributed microgrid EMS.

In this context, we propose a photovoltaic system, a battery, a load with variable demanded power and a connection to the public grid. The global system will be controlled and managed by an artificial neural network. A set of rules and conditions are considered to develop a system management algorithm which ensures a permanent power supply to the consumers. The random behavior of the solar system and the state of charge of the battery should be taken into account. Based on the aforementioned rules, neural networks are trained and used to ensure an optimal and reliable management of the energy produced by the photovoltaic system and the management of the battery charge and discharge (Protection against overcharge and deep discharge). This paper is divided into four sections: The first section describes the system under study and its main components. The second section presents the strategy and the management tool. The third section deals with the neural network training and the discussion of the test results obtained. The fourth and the final section is a conclusion that summarizes the work developed.

\section{PRESENTATION OF THE STUDIED SYSTEM}

The system studied is constituted mainly of; solar panels [8]. A DC/DC converter, which allows to reach the point of maximum power using the MPPT control "perturb observe" [9]. A battery, whose objective is to store energy in order to compensate for the power level demanded by the loads during the absence of the operating condition 'solar irradiation' of the photovoltaic system [10]. A bidirectional DC/DC converter, allows the current to flow in two directions in order to manage the charge and discharge of the battery [11], [12]. The flow will be controlled by the neural network which will assign states to the switch (S1 and S2). A $\mathrm{DC} / \mathrm{AC}$ inverter's role is to give an alternating current to the consumers. When it comes to switches, two switches (SL2 and SL3) do the role of connecting and disconnecting loads, and one (S_G) for switching to connect mode [13], [14]. As shows the Figure 1, the studied system architecture. The selection of the solar panel can be based on more important factors such as power output, semiconductor material (multicrystalline, monocrystalline, amorphous silicon), battery charging voltage. The Table 1, show the main characteristics of the used photovoltaic model.

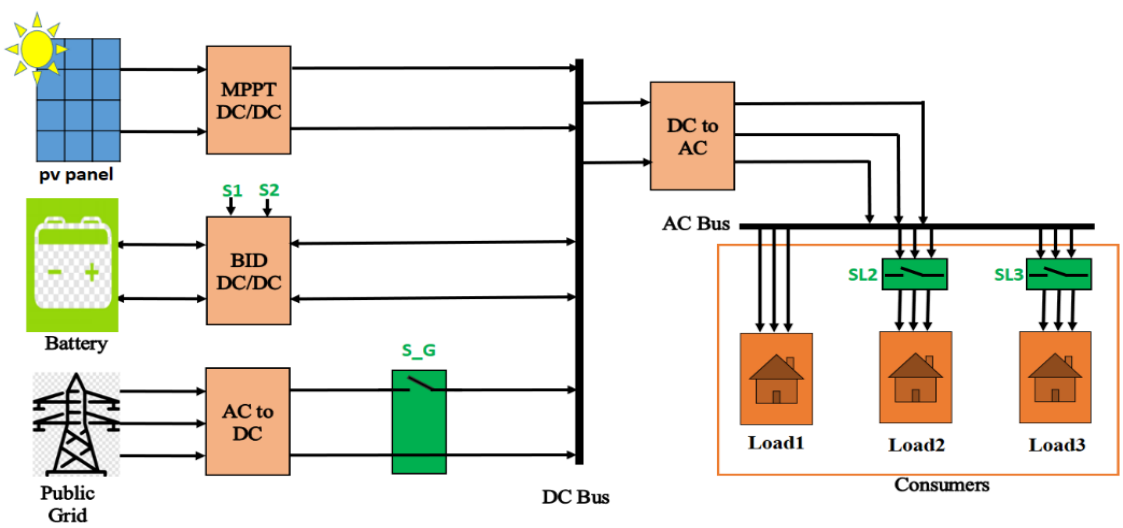

Figure 1. The studied system architecture

Table 1. Characteristics of photovoltaic panel

\begin{tabular}{lc}
\hline \multicolumn{1}{c}{ Characteristic } & Specification \\
\hline Maximum power (Pmax) & $55.8 \mathrm{~W}$ \\
Voltage at Pmax & $17.8 \mathrm{~V}$ \\
Current at Pmax & $3.1 \mathrm{~A}$ \\
Short-circuit current (Isc) & $3.6 \mathrm{~A}$ \\
Open-circuit voltage (Voc) & $22 \mathrm{~V}$ \\
\hline
\end{tabular}

Energy management system and supervision in a micro-grid using artificial neural ... (Ezzitouni Jarmouni) 


\section{THE MANAGEMENT STRATEGY}

During of the system operation, a battery placed in a grid can undergo overloads for exceeding its maximum state of charge (SOCmax), deep discharges for decreasing its SOC above its minimum state of charge (SOCmin) [15]-[18]. In addition, the power supply to the installation can be interrupted in the event of a lack of renewable energy or in the case of a battery discharge (SOC $<\mathrm{SOCmin}$ ). Based on these remarks, we propose a management algorithm for our system, which will be used as a basis for the construction of an intelligent management model 'artificial neural network'. The model ANN should; protect the battery from deep discharges and overcharging, guarantee the continuous supply of the installation by switching to the public electricity network in the case of absence of renewable energies or battery discharge, use renewable energy sources as much as possible and the following diagram shows the different scenarios that can be encountered during system operation and the actions to be taken. The management strategy is shown in Figure 2.

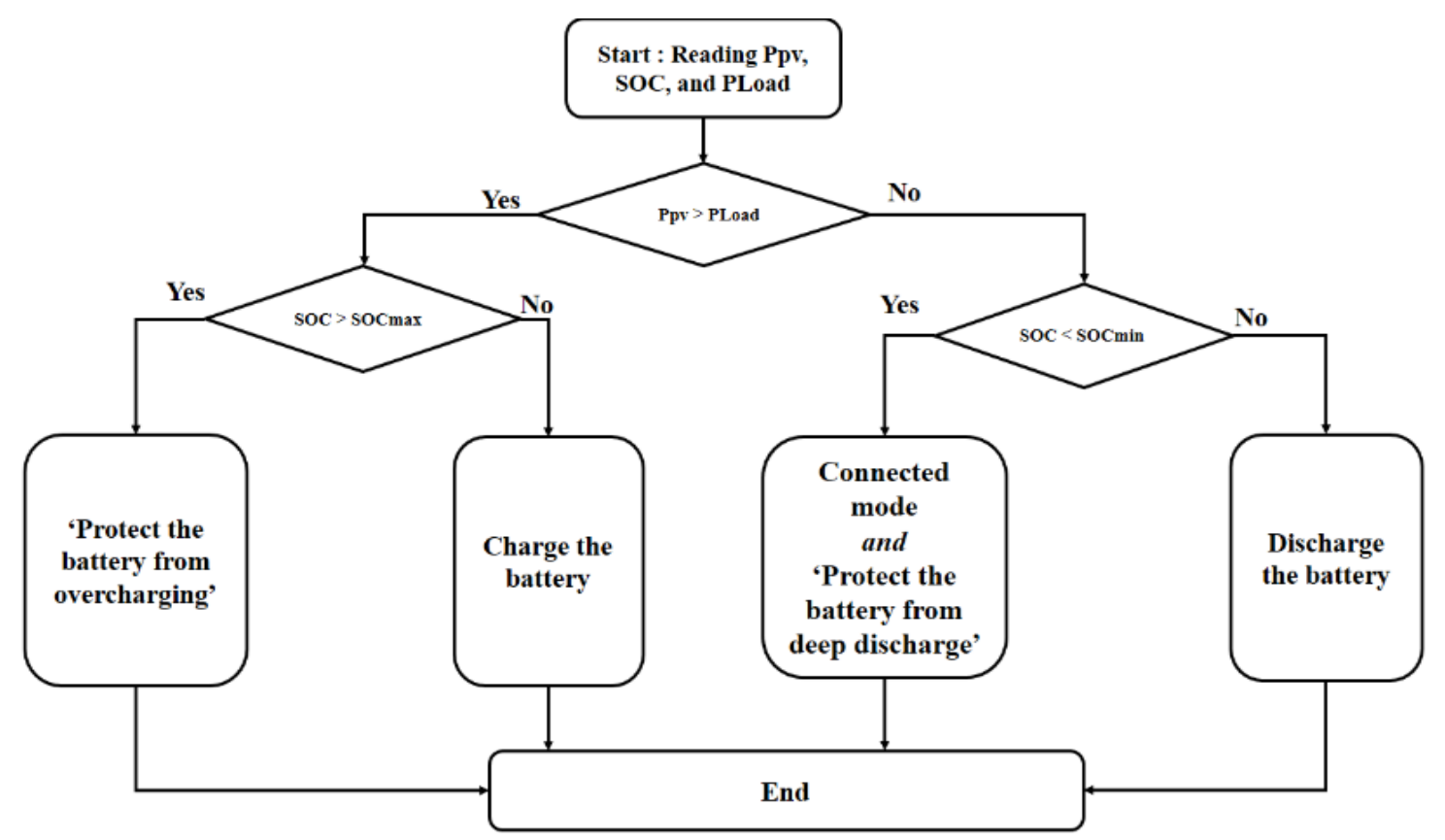

Figure 2. The management chart of the studied system

\subsection{System for calculating the power demand by the loads}

The load system consists of three loads, the first is a critical load permanently connected, the second and the third load connecting and disconnecting to the grid in a random way. Figure 3 shows the power demanded by the load is recognized via the states of switches SL2 and SL3. The following algorithm summarizes the calculation of the power demanded by the three loads in KW. The calculation algorithm is implemented in a MATLAB function that takes the state of the switches SL2 and SL3 and returns the power demanded by the consumers.

$P L \_D=P L 1$;

If $(S L 2=0 \& S L 3=0)$

Then $P L \_D=P L 1$;

Else if $(S L 2=1 \& S L 3=0)$

Then PL_D $=P L 1+P L 2$;

Else if $(S L 2=0 \& S L 3=1)$

Then PL_D = PL1 + PL3;

Else if $(S L 2=1 \& S L 3=1)$

Then PL_D $=$ PL1 + PL2 +PL3; 

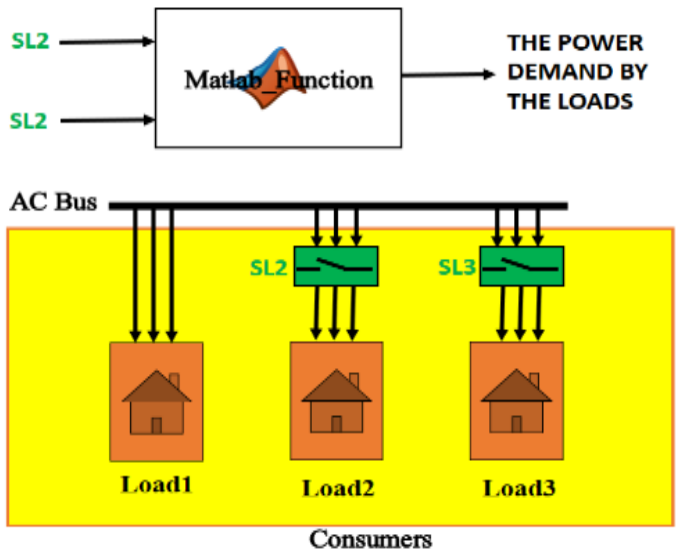

Figure 3. The power demanded by the consumers

\subsection{Artificial neural network}

In the face of increasing energy demand and decreasing fossil energy supply [19], the development of new management techniques has become an obligation. In this section, we will present an electrical energy management system based on multilayer perceptron 'artificial neural networks. The ANN model has three input vectors which are the power generated by the PV array (Ppv), the state of charge of the battery (SOC) and the power demanded by the loads (PL). On the output side there are also three vectors, two output vectors (S1 and S2) for controlling the charge and discharge of the battery and the third (S_G) output vector is used to control the connected and disconnected mode of the system with the public grid. To evaluate the performance of the various developed models, we used two statistical indicators: The correlation coefficient $\mathrm{R}$ and the mean square error MSE [20], [21]. To determine the most suited architecture of the network to be used, we varied the number of hidden layers, the number of neurons in a hidden layer, the transfer functions, the number of iterations and the learning algorithms [22].

\subsection{Characteristics of the ANN model}

After several tests, we decided to work with a three-layer model, an input layer, an output layer and a hidden layer. In order to choose the characteristics of the ANN model adequate for our problem (The number of neurons in the hidden layer, the learning algorithm and the activation function ...), several tests are performed [23]. Which can be summarized in three main cases; in this section, we present a part of the work that we have done to find the best architecture for our network. Three main cases can be studied in each case a learning algorithm has been set. And we varied the number of neurons in the hidden layer and the activation functions several times, in order to get acceptable results. The choice of the training algorithms shown in the following three cases has been made after various tests. And the chosen algorithms are the ones that have given more acceptable results compared to others.

The case 1: In this case, we chose the algorithm Levenberg-Marquardt and we changed the number of neurons of the hidden layer, the activation function of the hidden layer and the output layer. Afterwards, the results of each test have been taken. Table 2, shows the different obtained results.

Table 2. The Levenberg-Marquardt algorithm

\begin{tabular}{ccccccc}
\hline Hidden layer & Output layer & Labels & Architecture & R factor & MSE $\left({\left.\mathrm{x} 10^{-4}\right)}^{\text {Number of iterations }}\right.$ \\
\hline Purelin & Purelin & PP & {$[3-8-3]$} & 0.908 & 432 & 29 \\
Purelin & Logsig & PL & {$[3-9-3]$} & 0.994 & 1330 & 77 \\
Purelin & Tansig & PT & {$[3-4-3]$} & 0.996 & 3.84 & 49 \\
Tansig & Tansig & TT & {$[3-14-3]$} & 0.998 & 4.14 & 37 \\
Tansig & Purelin & TP & {$[3-8-3]$} & 0.996 & 1.99 & 54 \\
Tansig & Logsig & TL & {$[3-11-3]$} & 0.966 & 1310 & 51 \\
Logsig & Logsig & LL & {$[3-5-3]$} & 0.998 & 1320 & 85 \\
Logsig & Tansig & LT & {$[3-7-3]$} & 0.996 & 2.89 & 144 \\
Logsig & Purelin & LP & {$[3-8-3]$} & 0.998 & 9.13 & 110 \\
\hline
\end{tabular}

The case 2: In this case, we chose The Resilient Backpropagation algorithm, and similar to case 1, we changed the number of neurons in the hidden layer, the activation function of the hidden layer and the output layer. Table 3 , shows the different results obtained. 
Table 3. The resilient backpropagation algorithm

\begin{tabular}{ccccccc}
\hline Hidden layer & Output layer & Labels & Architecture & R factor & MSE $\left(\times 10^{-4}\right)$ & Number of iterations \\
\cline { 1 - 5 } Purelin & Purelin & PP & {$[3-7-3]$} & 0.79 & 905 & 46 \\
Purelin & Logsig & PL & {$[3-9-3]$} & 0.976 & 1350 & 200 \\
Purelin & Tansig & PT & {$[3-6-3]$} & 0.978 & 101 & 82 \\
Tansig & Tansig & TT & {$[3-8-3]$} & 0.990 & 46.5 & 621 \\
Tansig & Purelin & TP & {$[3-5-3]$} & 0.981 & 87.8 & 191 \\
Tansig & Logsig & TL & {$[3-6-3]$} & 0.996 & 1330 & 271 \\
Logsig & Logsig & LL & {$[3-5-3]$} & 0.987 & 1340 & 632 \\
Logsig & Tansig & LT & {$[3-11-3]$} & 0.996 & 10.2 & 130 \\
Logsig & Purelin & LP & {$[3-5-3]$} & 0.985 & 56.99 & 218 \\
\hline
\end{tabular}

The case 3: In this case, we chose the scaled conjugate gradient algorithm, and like cases 1 and 2, we changed the number of neurons in the hidden layer, the activation function of the hidden layer and the output layer. Table 4, shows the different results obtained.

Table 4. The scaled conjugate gradient algorithm

\begin{tabular}{ccccccc}
\hline Hidden layer & Output layer & Labels & Architecture & R factor & MSE $\left(\times 10^{-4}\right)$ & Number of iterations \\
\cline { 1 - 5 } Purelin & Purelin & PP & {$[3-9-3]$} & 0.776 & 98.7 & 40 \\
Purelin & Logsig & PL & {$[3-16-3]$} & 0.971 & 1360 & 121 \\
Purelin & Tansig & PT & {$[3-5-3]$} & 0.985 & 66.7 & 148 \\
Tansig & Tansig & TT & {$[3-10-3]$} & 0.992 & 29.8 & 83 \\
Tansig & Purelin & TP & {$[3-7-3]$} & 0.977 & 111 & 264 \\
Tansig & Logsig & TL & {$[3-6-3]$} & 0.988 & 1340 & 107 \\
Logsig & Logsig & LL & {$[3-5-3]$} & 0568 & 1950 & 73 \\
Logsig & Tansig & LT & {$[3-4-3]$} & 0.993 & 27.7 & 174 \\
Logsig & Purelin & LP & {$[3-9-3]$} & 0.995 & 24.1 & 195 \\
\hline
\end{tabular}

\subsection{Comparison between the three algorithms}

Table 5, shows the best results obtained in the three test cases. We can see, that with the LevenbergMarquardt algorithm we have obtained the best values of the MSE and of the R coefficient. The mean squared error arrived in this case at the value $1.99 .10^{-4}$ at 54 iterations, this value means that we have a good convergence of the network output to the desired output [24], [25]. The ANN model chosen as shown in Figure 4, consists of three layers, three output vectors, three input vectors, each vector is of dimension $6000 \times 1$. The input and output layer contain three neurons and the hidden layer contains eight neurons.

Table 5. Comparison of the best results obtained in the three cases.

\begin{tabular}{ccccc}
\hline Algorithms & Labels & Architecture & R factor & MSE $\left(\times 10^{-4}\right)$ \\
\hline Levenberg-Marquardt & TP & {$[3-8-3]$} & 0.996 & 1.99 \\
Resilient Back propagation & LT & {$[3-11-3]$} & 0.996 & 10.2 \\
Scalde Conjugale Gradient & LP & {$[3-9-3]$} & 0.995 & 24.1 \\
\hline
\end{tabular}

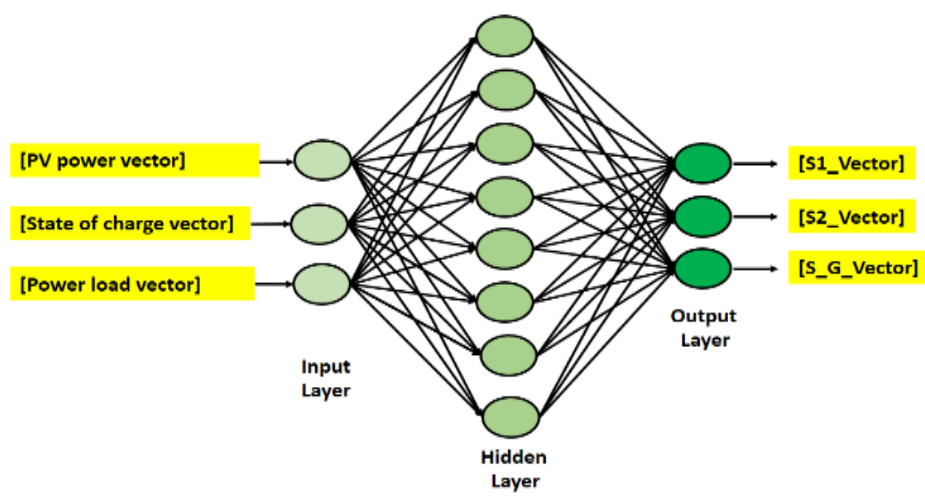

Figure 4. The neural network architecture 


\section{DISCUSSION OF THE RESULTS}

This part is subdivided into two phases; in the first phase, the different steps and results of the ANN model simulation will be presented, accompanied by discussions of the results obtained. The second phase will be devoted to the testing and validation of the ANN model under a variety of system test conditions.

\subsection{Training of the chosen model under MATLAB}

The Figure 5 shows the relationship between the observed values and those estimated by the ANN model during the different phases (Training, validation and test). This part, presents the different factors that prove the robustness and reliability of the model developed. The Figure 6 shows the structure of the network neural under MATLAB such as the numbers of inputs/outputs, the number of layers and activation functions used.
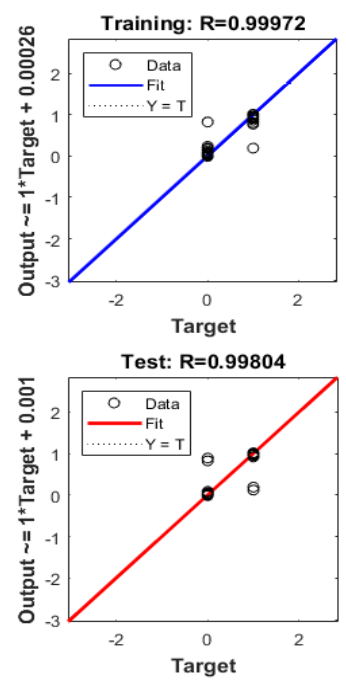

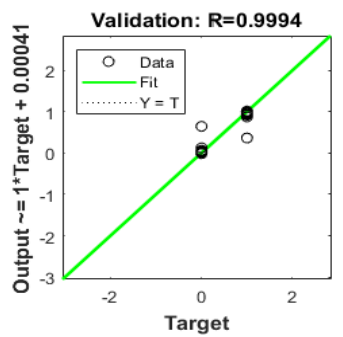

All: $\mathbf{R}=\mathbf{0 . 9 9 9 4 2}$

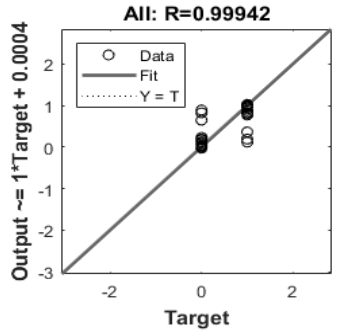

Figure 5. R-factor for the chosen model [3-8-3]

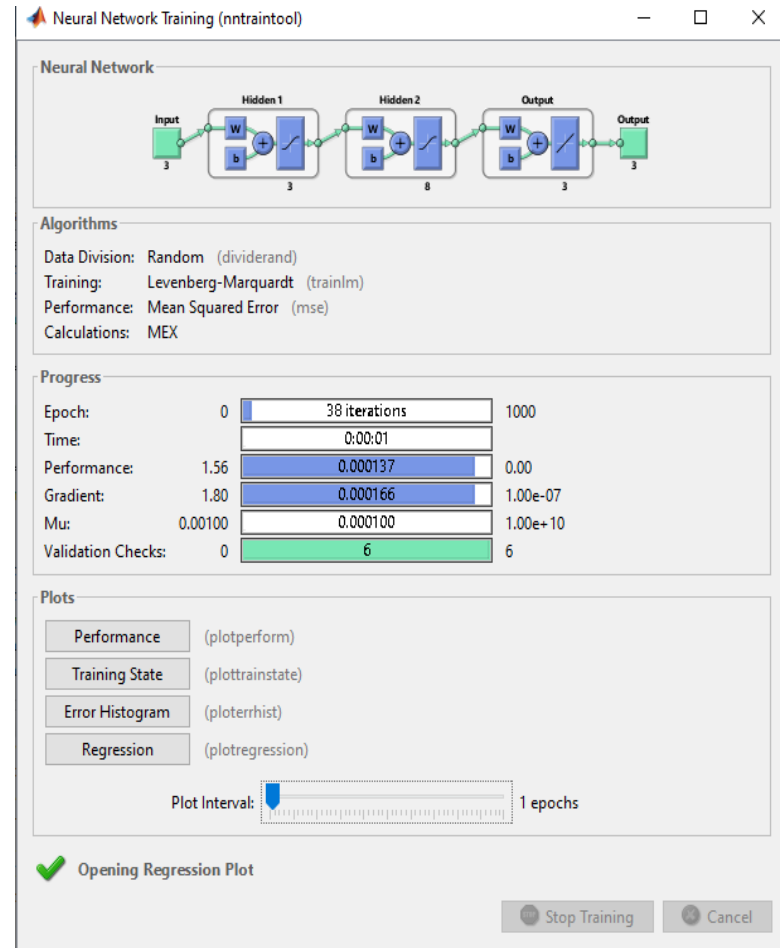

Figure 6. The neural network performance 


\subsection{The management model under different conditions of test}

To test the efficiency and the robustness of the ANN management model, we will put the system under different test conditions.

- Power demanded by the loads

The Figure 7 shows the power demanded by the consumers related to the state of the switches (SL2 and SL3) connecting the loads to the electrical grid.
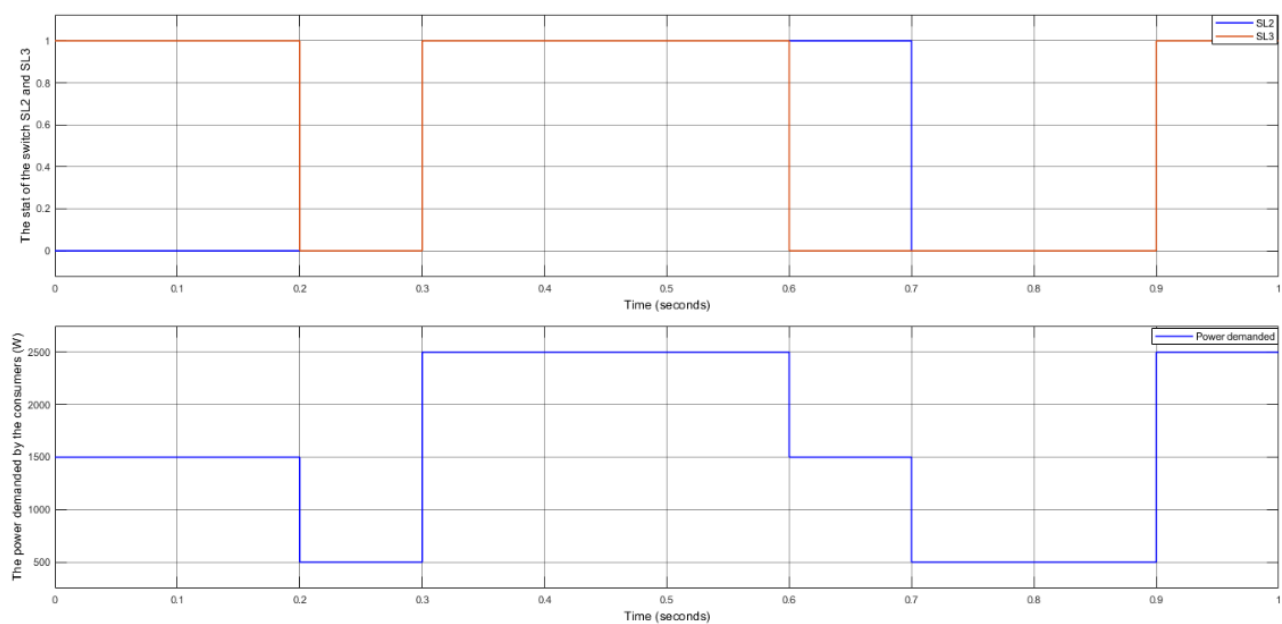

Figure 7. The power demanded by the loads

\section{The case 1: The battery charge is higher than the SOCmin}

In this case if the irradiation is insufficient for the PV array to produce the demanded power, the battery becomes the main generator to supply the consumer. For a better analysis of the Figure 8 , we will take two-time intervals;

The first from $0.2 \mathrm{~s}$ to $0.3 \mathrm{~s}$ : The power generated by the photovoltaic generator is higher than the power demanded by the load, as a consequence of these conditions, the ANN management model imposes the charging of the battery (from the photovoltaic system) by setting the switch S2 to 1 .

The second from 0.9s to 1s: The power generated by the PV array is lower than the power demanded by the load, as a result of these conditions, the ANN management model imposes the discharge of the battery (to ensure the supply of electricity to the consumer) by setting the switch S1 to 1 .

In this case, the switch state $\mathrm{S} \_\mathrm{N}$ is unchanged because the battery is in a state of charge (SOC > SOCmin), so no connection to the public grid is needed.
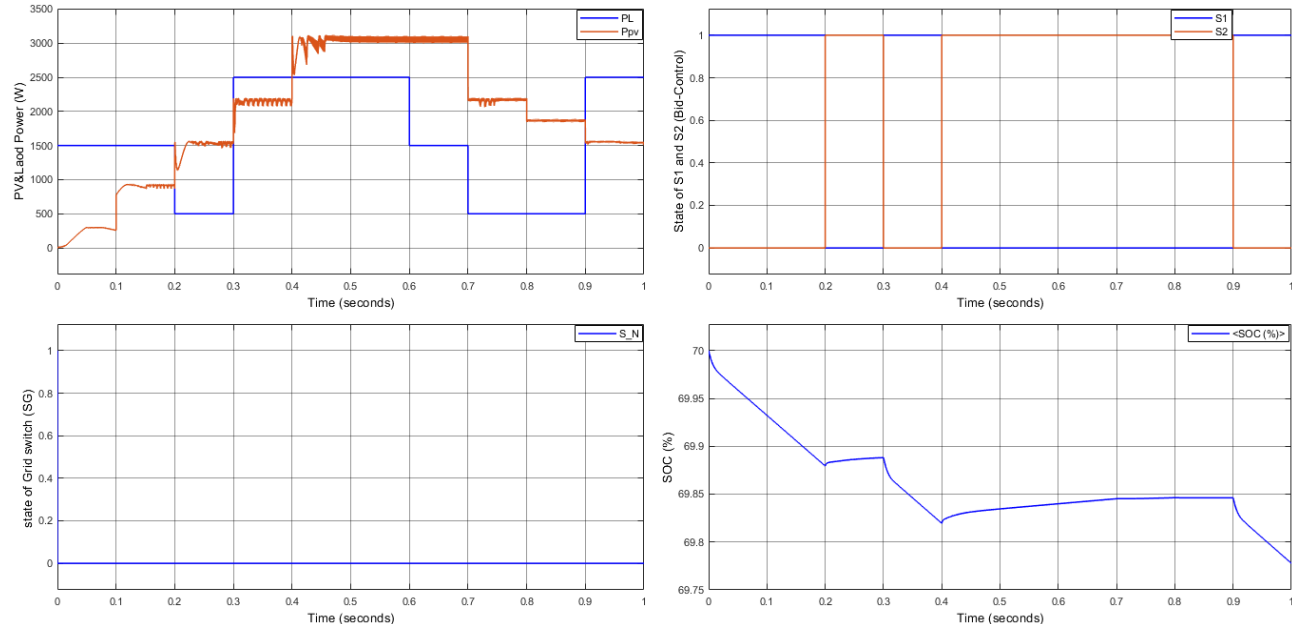

Figure 8 . The case 1 


\section{The case 2: The battery charge is below the SOCmin}

In this case the battery state of charge is insufficient (SOC $<\mathrm{SOCmin}$ ) to replace the PV array, when the power demanded by the load is higher than the power generated by the PV system. Like case 1, for a better analysis of the Figure 9, we will take two-time intervals;

The first from 0.2s to 0.3s: The power generated by the photovoltaic generator is higher than the power demanded by the load, as a result of these conditions, the ANN management model imposes the charging of the battery (from the photovoltaic system) by setting the switch S2 to 1 .

The second from $0.9 \mathrm{~s}$ to $1 \mathrm{~s}$ : The power generated by the PV array is lower than the power demanded by the load, as a result of these conditions, the ANN management model imposes the charging of the battery (from the public grid) by setting switch S1 to 1 , and the switchover to connected mode by setting S_N to 1 .
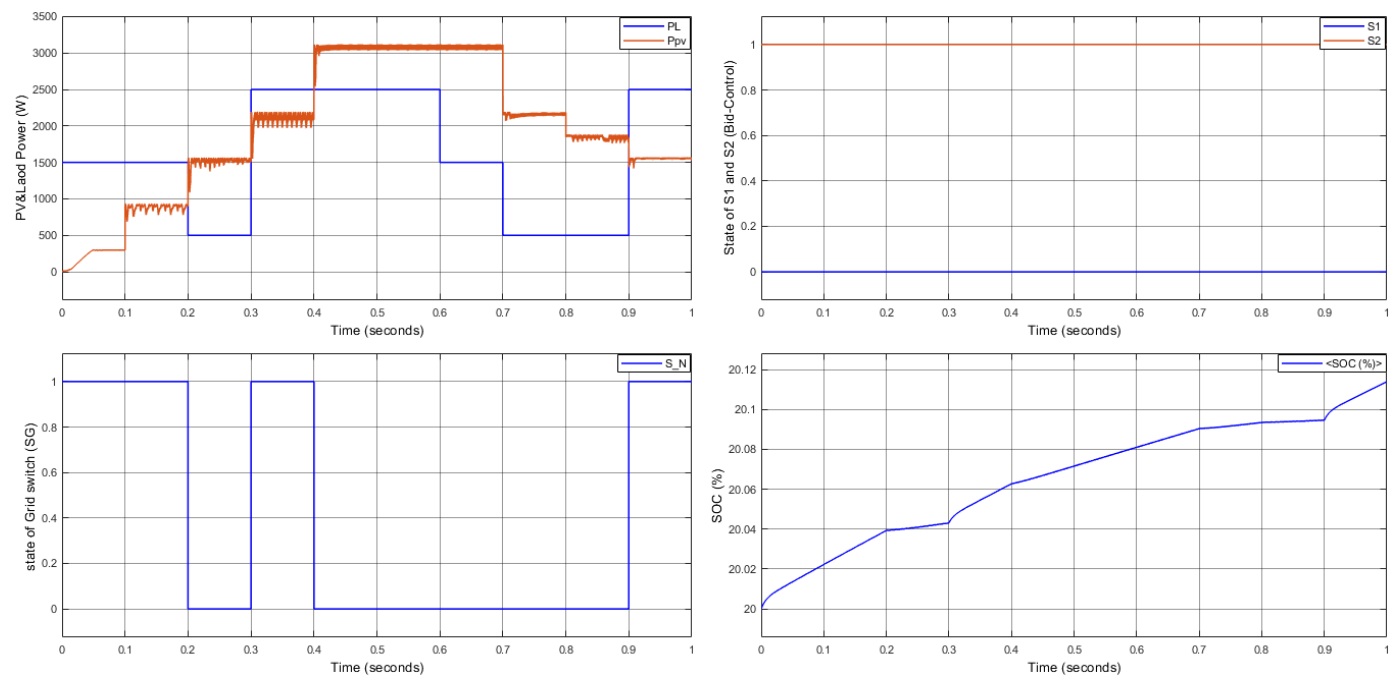

Figure 9. The case 2

\section{CONCLUSION}

With the fast growing of smart grids and the combination of electrical energy sources, the development of new management techniques simultaneously with this expansion has become an essential point. In this context, a model based on artificial neural networks has been developed. The latter is able to perform the global management of the system, such as charging and discharging the battery while ensuring the protection of the battery against overcharging and deep discharging. The aforementioned model is also able to switch to the connected mode in order to ensure the permanent supply to the consumers with reliability, robustness and a minimal use of the public grid in the different operating modes.

\section{REFERENCES}

[1] IEA. Available online: https://www.iea.org/renewables2019/ (accessed on 21 October 2019).

[2] L. Chen. "SMES-battery energy storage system for the stabilization of a photovoltaic-based microgrid," IEEE Trans. Appl. Supercond., vol. 28, no. 4, pp. 1-7, June 2018, doi: 10.1109/TASC.2018.2799544.

[3] V. Rallabandi, O. M. Akeyo, N. Jewell, and D. M. Ionel, "Incorporating battery energy storage systems into multimw grid connected PV systems," IEEE Trans. Ind. Appl., vol. 55, no. 1, pp. 638-647, Jan.-Feb. 2019, doi: 10.1109/TIA.2018.2864696.

[4] Z. Cheng, J. Duan, and M.-Yuen Chow, "To centralize or to distribute: that is the question: a comparison of advanced microgrid management systems," IEEE Ind Electron Mag. vol. 12, no. 1, pp. 6-24, 2018, doi: 10.1109/MIE.2018.2789926.

[5] H. Shareef, M. S. Ahmed, A. Mohamed, and E. Al Hassan, "Review on home energy management system considering demand responses, smart technologies, and intelligent controllers," IEEE Access, vol. 6, pp. 2449824509, 2018, doi: 10.1109/ACCESS.2018.2831917.

[6] S. F. Rafique, Z. Jianhua, "Energy management system, generation and demand predictors: a review," IET Gener Transm Distrib., vol. 12, no. 3, pp. 519-530, 2017, doi: 10.1049/iet-gtd.2017.0354.

[7] M. W. Khan, J. Wang, M. Ma, L. Xiong, P. Li, and F. Wu, "Optimal energy management and control aspects of distributed microgrid using multi-agent systems," Sustain Cities Soc., vol. 44, pp. 855-870, 2019, doi: 10.1016/j.scs.2018.11.009. 
[8] S. Rahman, and H. Abdul Rahman, "Use of photovoltaics in microgrid as energy source and control method using MATLAB/Simulink", in International Journal of Electrical and Computer Engineering (IJECE), vol. 6, no. 2, pp. 851-858, April 2016.

[9] A. M. Atallah, A. Y. Abdelaziz, and R. S. Jumaah, "Implementation of perturb and observe mppt of pv system with direct control method using buck and buck boost converters," Emerging Trends in Electrical, Electronic Instrumentation Engineering, vol. 1, no. 1, pp. 21-44, February 2014.

[10] H. Abdi, B. Mohammadi, S. Javadi, and A. Reza Khodaei, "Energy storage systems," in Distributed Generation Systems Design, Operation and Grid Integration, 2017, pp. 333-368, doi: 10.1016/B978-0-12-804208-3.00007-8.

[11] K. S. R. Mawonou, A. Eddahech, D. Dumur, E. Godoy, D. Beauvois, and M. Mensler, "Li-ion battery pack SoC estimation for electric vehicles," IECON 2018 - 44th Annual Conference of the IEEE Industrial Electronics Society, 2018, doi: 10.1109/IECON.2018.8591187.

[12] G. S. d. Sandtos, F. J. Grandinetti, R. A. Rocha Alves, and W. de Queiróz Lama, "Design and simulation of an energy storage system with batteries lead acid and lithium-ion for an electric vehicle Battery vs. conduction cycle efficiency analysis," in IEEE Latin America Transactions, vol. 18, no. 8, August 2020, doi: 10.1109/TLA.2020.9111669.

[13] A. Chakir et al., "Optimal energy management for a grid connected PV-battery system," in Energy Reports, vol. 6, pp. 218-231, 2020, doi: 10.1016/j.egyr.2019.10.040.

[14] V. M. Jyothi, T. V. Muni, and S. Lalitha, "An optimal energy management system for PV/battery standalone system," in International Journal of Electrical and Computer Engineering (IJECE), vol. 6, no. 6, pp. 2538-2544 December 2016, doi: 10.11591/ijece. v6i6.11479.

[15] Zaheeruddin, and M. Manas, "Renewable energy management through microgrid central controller design: An approach to integrate solar, wind and biomass with battery," IET Power Electronics, vol. 1, pp. 156-163, November 2015, doi: 10.1016/j.egyr.2015.06.003.

[16] A. Merabet, K. T. Ahmed, H. Ibrahim, R. Beguenane, and A. M. Y. M. Ghias, "Energy management and control system for laboratory scale microgrid based WindPV-battery," IEEE Transactions on Sustainable Energy, vol. 8, no. 1, pp. 145-154, Jan. 2017, doi: 10.1109/TSTE.2016.2587828.

[17] M. S. Tamrin and M. R. Ahmad, "Simulation of adaptive power management circuit for hybrid energy harvester and real-time sensing application," International Journal of Power Electronics and Drive System (IJPEDS), vol. 11, no. 2, June 2020, doi: 10.11591/ijpeds.v11.i2.pp658-666.

[18] Muhardika, and Syafii, "Design of arduino-based loading management system to improve continuity of solar power supply," Indonesian Journal of Electrical Engineering and Computer Science, vol. 20, no. 3, pp. 1677-1684, December 2020, doi: 10.11591/ijeecs.v20.i3.pp1677-1684.

[19] F. Martins, C. Felgueiras, M. Smitkova, and N. Caetano, "Analysis of fossil fuel energy consumption and environmental impacts in european countries," Energy Procedia, vol. 153, pp. 107-111, March 2018, doi: 10.1016/j.egypro.2018.10.050.

[20] S. Altikat, A. Gulbe, H. K. Kucukerdem, and A. Altikat, "Applications of artificial neural networks and hybrid models for predicting CO2 flux from soil to atmosphere," International Journal of Environmental Science and Technology, vol. 17, no. 12, pp. 4719-4732, 2020, doi: 10.1007/s13762-020-02799-6.

[21] A. F. M. Nor, S. Salimin, M. N. Abdullah, and M. N. Ismail, "Application of artificial neural network in sizing a stand-alone photovoltaic system: a review," International Journal of Power Electronics and Drive System (IJPEDS), vol. 11, no. 1, March 2020, doi: 10.11591/ijpeds.v11.i1.pp342-349.

[22] G. Mustafaraja, "Prediction of room temperature and relative humidity by autoregressive linear and nonlinear neural network models for an open office," Energy and Buildings, vol. 43, no. 6, pp. 1452-1460, June 2011, 10.1016/j.enbuild.2011.02.007.

[23] A. Zouidi, M. Stambouli, A. Chaari, and F. Fnaiech, "Nonlinear continuous time modeling of a high pressure mercury vapor discharge lamp using feed forward back-propagation neural networks," in IEEE International Conference on Industrial Technology (ICIT), Yasmine Hammamet, Tunisie, 2004, doi: 10.1109/ICIT.2004.1490147.

[24] F. Saadaoui, K. Mammar, and A, Hazzab, "Modeling of photovoltaic system with maximum power point tracking control by neural networks", in International Journal of Power Electronics and Drive System (IJPEDS), vol. 10, no. 3, pp. 1575-1591, Sep 2019, doi: 10.11591/ijpeds.v10.i3.pp1575-1591.

[25] N. H. Christiansen, P. E. T. Voie, O. Winther, and J. Høgsberg, "Comparison of neural network error measures for simulation of slender marine structures," Journal of Applied Mathematics, vol. 4, pp. 1-11, 2014, doi: $10.1155 / 2014 / 759834$. 


\section{BIOGRAPHIES OF AUTHORS}
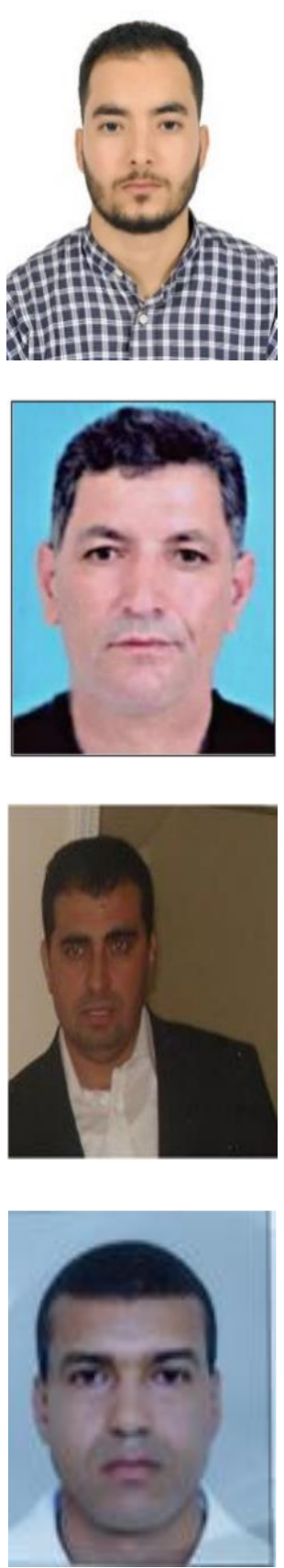

Jarmouni Ezzitouni, PhD student, received his master degree in electrical engineering from faculty of science and technology Settat, in 2019, and he is currently a qualified secondary school mathematics teacher, at the Ministry of National Education, Morocco. His research areas include, smart grid, renewable energy and artificial intelligence. Laboratory of Radiation-Matter and Instrumentation (RMI), The Faculty of Sciences and Technology, Hassan 1st University, Morocco. BP : 577, route de Casablanca. Settat, Morocco. Email: ezzitouni.jarmouni@gmail.com

Ahmed Mouhsen, received his Ph.D. degree in Electronics from the University of Bordeaux, France, in 1992, and he is currently a Professor at the Electrical Engineering Department, Faculty of Sciences and Technologies, Hassan I University, Settat, Morocco. His research interest focuses on embedded systems, wireless communications and information technology. Laboratoire d'Ingénierie, de Management Industriel et d'Innovation (LIMII) Faculté' des Sciences et techniques (FST) Hassan First Université BP : 577, route de Casablanca. Settat, Morocco. Email: ahmed.mouhsen@uhp.ac.ma

Mohamed Lamhamdi, holds a PhD (2008) in materials and technology of electronics components from Paul Sabatier University Toulouse France. After four years' research engineer Grand Gap Rectifier project at STMicroelectronics \& GREMAN-University of Tours. in November 2011 he has been an assistant professor at national school of applied science khouribga Morocco, where he became the technical manager of the Electronics Signals and Systems (ESS) group. in January 2018, he joined the faculty of science and technology in Settat, Morocco, where he became member of the RMI Laboratory (Rayonnement-Matière \& Instrumentation). Current research topics include, MEMS sensors for RF applications, materials sciences, intelligent systems and energy. Email: mohamed.lamhamdi@gmail.com

Hicham Ouldzira, he obtained his doctorate from Hassan I University in 2020. in 2020, he joined The National School of Applied Sciences of SAFI, Laboratory of Mechanical, Engineering, Industrial Management and Innovation, The Faculty of Sciences and Technology, Hassan 1st University, PO Box 577, Settat, Morocco. His research interest focuses on electrical engineering, internet of things, embedded systems. Email: odzira@yahoo.fr 